\title{
Análise da Preocupação das Atuais Políticas Agrícolas e Ambiental Brasileiras com a Mitigação dos Gases Causadores do Efeito Estufa
}

\author{
Rodrigo Damasceno \\ Economista e Pesquisador do CEPEA/ESALQ/USP \\ Carlos José Caetano Bacha \\ Professor Titular da ESALQ/USP \\ Silvia Helena Galvão de Miranda \\ Professora Associada da ESALQ/USP
}

\section{Resumo}

Esse trabalho analisa a preocupação das políticas agrícolas e ambientais brasileiras com a mitigação da emissão de gases causadores do efeito estufa. Ainda que a preocupação das políticas agrícolas seja, basicamente, com o estímulo à produção agropecuária e a das políticas ambientais seja, em parte, a regulamentação da produção agropecuária de modo a impactar minimamente o meio ambiente, há programas em ambas políticas que permitem a redução da emissão de gases causadores do efeito estufa. No entanto, esses programas, no que se refere à política agrícola, não adquirem a maior importância dentro dessa política.

Palavras chave: efeito estufa; mitigação; política agrícola; política ambiental; Brasil.

\section{Abstract}

This paper analyzes the concern of both Brazil's agricultural and environmental policies with the mitigation of the greenhouse gases emission. Although agricultural policies are primarily concerned with stimulating agricultural production and a big share of environmental policies pay attention to the regulation of agricultural production in order to have a minimal impact on the environment, there are programs in both policies that would led to the mitigation of greenhouse gases emission. However, these programs inside of agricultural policies do not reach the same importance as the ones concerning to stimulating agricultural production.

Key words: greenhouse effect; mitigation; agricultural policy; environmental policy; Brazil. 


\section{INTRODUÇÃO}

O objetivo deste artigo é analisar a preocupação que as políticas agrícolas e ambientais adotadas no Brasil têm com a mitigação da emissão de gases causadores do efeito estufa comparando com a sua preocupação com a expansão da produção agropecuária.

Os gases causadores do efeito estufa são o gás metano $(\mathrm{CH} 4)$ e o óxido nitroso (N20). 0 óxido de nitrogênio (NOx) e o monóxido de carbono (CO) são precursores de gases de efeito estufa, pois o NOx é oxidado em NO2 e o CO se transforma em CO2 na atmosfera. Esses gases causam aumento da temperatura na Terra à medida que impedem que a radiação infravermelha, refletida pela superfície terrestre, volte para o espaço.

A agropecuária é, no Brasil, responsável por 31\% da emissão desses gases, sendo a pecuária bovina a principal emissora desses gases dentro da agropecuária. A fermentação entérica representou 56,77\% das emissões desse setor e 17,6\% das emissões nacionais no ano de 2015.

Segundo Bacha (2012), política agrícola é o conjunto de instrumentos que visam estimular e/ou regulamentar a produção agropecuária. Essa política tem se baseado no crédito rural, nos preços mínimos, no seguro rural, na pesquisa e extensão rural, bem como no abastecimento alimentar da população. À política agrícola se vincula algumas políticas ambientais, em especial, as referentes ao uso de florestas e recursos hídricos.

Há ampla literatura analisando essas políticas agrícola, florestal e de recursos hídricos. Não a esgotando, têm-se, por exemplo, os trabalhos de Araújo (1983), Sayad (1984), Bacha e Silva (2005), que analisam a política de crédito rural no Brasil. Sobre preços mínimos, têm-se: Rezende (2001), Stefanelo (2005) e Almeida (2014). Sobre seguro rural destacam-se os trabalhos de Caffagani (1998) e Ozaki (2008). A pesquisa agropecuária é avaliada por Portugal e Contini (1997) e Alves (2010); e a extensão rural, por Lima (2000) e Peixoto (2014). A política florestal é analisada por Bacha (2004) e a política de recursos hídricos por Borsoi e Torres (1997) e Buriti e Barbosa (2014).

Esses trabalhos, como já dito, não esgotam os temas tratados mas permitem avaliar, em diferentes momentos das últimas cinco décadas, as evoluções ocorridas 
nas citadas políticas. Mas o foco desses trabalhos não é a preocupação que as políticas agrícolas possam ter com a mitigação dos gases causadores do efeito estufa.

Adentrando nessa lacuna do conhecimento, o presente artigo apresenta um panorama atual das políticas agrícolas e ambientais (essas últimas que se ligam com a agropecuária) e ressalta como seus programas têm tratado da mitigação dos gases causadores do efeito estufa (GEE).

0 restante do artigo é composto de mais três seções. Na seção 2 se analisam as principais políticas agrícolas (de crédito rural, de preços mínimos, de pesquisa agropecuária, extensão rural e abastecimento) focando, dentro delas, os programas que possam ter preocupação com a mitigação de GEE. Não se identificou essa preocupação na política de seguro rural e, portanto, essa última não é analisada neste artigo. A terceira seção do artigo analisa as principais políticas ambientais vinculadas com a agropecuária, que são a legislação florestal e a referente ao uso de recursos hídricos. A última seção do artigo apresenta as nossas considerações finais, seguidas da bibliografia citada.

\section{POLÍTICAS AGRÍCOLAS}

Os subitens a seguir expõem, dentro das políticas agrícolas convencionais, os programas que apresentam preocupação com a mitigação de GEE.

\subsection{POLÍTICA DE CRÉDITO RURAL}

Crédito rural é um mecanismo de concessão de crédito para a agropecuária a taxas de juros e condições de pagamento diferentes das determinadas pela política monetária (Bacha, 2012).

Até 2016, existiam, basicamente, três modalidades de crédito rural: custeio, investimento e comercialização. 0 crédito de custeio relaciona-se à necessidade de capital de giro para as atividades agrícolas. 0 crédito de comercialização está relacionado com políticas de preços mínimos. 0 crédito de investimento, em cuja modalidade há programas que permitem a mitigação de emissões de GEE, refere-se aos recursos captados para construção de instalações, compra de equipamentos e material genético e para o plantio de florestas. Dentro do crédito de investimento se destaca, considerando o objetivo deste artigo, o Programa ABC. 
O instrumento de crédito do Plano ABC é o Programa ABC, cuja finalidade é prover crédito agrícola destinado a projetos que visam a mitigação de emissões de GEE na agropecuária (Paixão e Bacha, 2015). A Resolução Bacen no 3.896/2010 prevê linha de crédito própria para o programa $\mathrm{ABC}$.

Paixão e Bacha (2015) destacam a diferença entre Plano e Programa ABC. 0 Plano estabelece as metas enquanto que o programa determina os meios para atingir as metas. É importante também destacar que tanto o Plano quanto o Programa ABC abrangem toda a agropecuária brasileira.

Sobre o Programa ABC e seu funcionamento, é importante ressaltar os trabalhos realizados pelo Observatório ABC. Esses relatórios analisam a destinação dos recursos do citado programa, bem como de seus subprogramas, entre as regiões do país. Esses relatórios também apontam caminhos para o aperfeiçoamento e o melhor funcionamento do programa uma vez que esse tema é importante nacional e internacionalmente.

É necessário destacar que o programa ABC teve início na safra 2010/2011 com a dotação autorizada de $\mathrm{R} \$ 2$ bilhões, porém a execução foi zero (Observatório ABC, 2013a), pois além do fato de ser uma linha de financiamento completamente nova, com fraca divulgação entre os agentes envolvidos, o BNDES era o único responsável financeiro por operar o citado programa. Na safra seguinte, o Banco do Brasil foi alçado também a esse posto e a implantação do programa começou a avançar. Vale destacar que o Banco do Brasil utiliza, além dos recursos específicos do Plano Agrícola e Pecuário para o programa $\mathrm{ABC}$, recursos da Poupança Rural para financiar os projetos de redução de emissões de GEE. Além da fonte de financiamento, a capacitação dos seus agentes financeiros e, posterior, treinamento dos atores envolvidos na tomada de crédito faz com que o funcionamento do programa, principalmente no seu início, tenha sido pautado pelo protagonismo do Banco do Brasil na execução do mesmo (Observatório ABC, 2013a).

Ainda segundo Observatório ABC (2013a), o BNDES aponta que um dos fatores responsáveis pela dificuldade em expandir o financiamento é o rigor em relação ao licenciamento ambiental e as diferenças nas legislações estaduais, visto 
que o BNDES não admite legislações estaduais e municipais para aprovação do projeto.

Observa-se no Gráfico 1 que os recursos alocados ao Programa ABC, bem como o número de contemplados, cresceu de 2011/12 a 2014/15, tendo ambos fortes recuos em 2015/16. As duas principais regiões contempladas com os recursos desse programa foram Sudeste e Centro-Oeste, que têm alternado a liderança em sua captação (Gráfico 2).

Gráfico 1 - Valor total dos contratos e Número Total de Contratos alocados pelo Programa ABC, por safra a partir de 2011/2012.

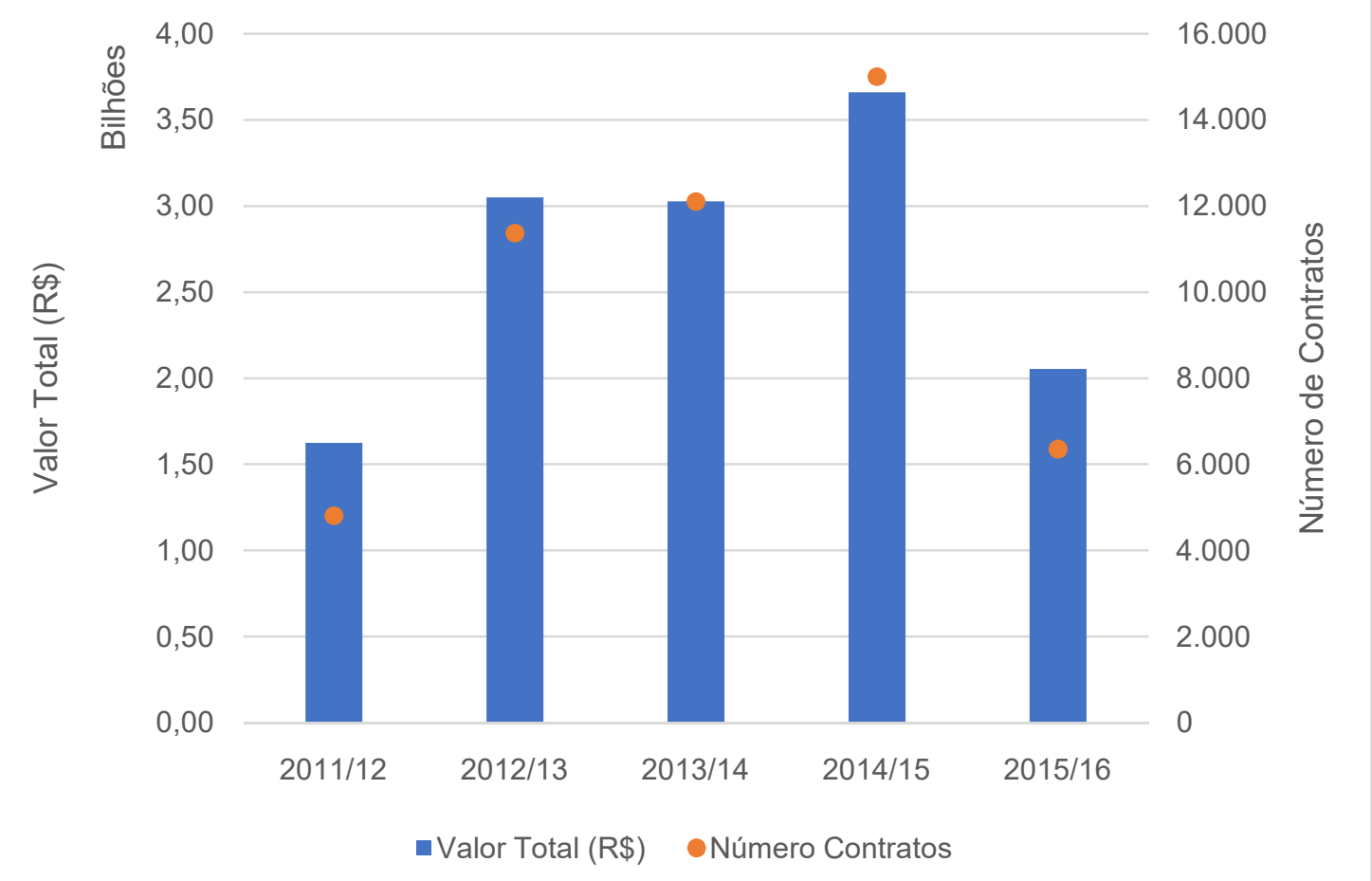

Fonte: Observatório ABC. Disponível em: < http://observatorioabc.com.br/sistema-abc/> 
Gráfico 2 - Evolução do desembolso do programa ABC por safra e por região. Em bilhões de reais. Brasil, safra 2011/12 a 2015/16

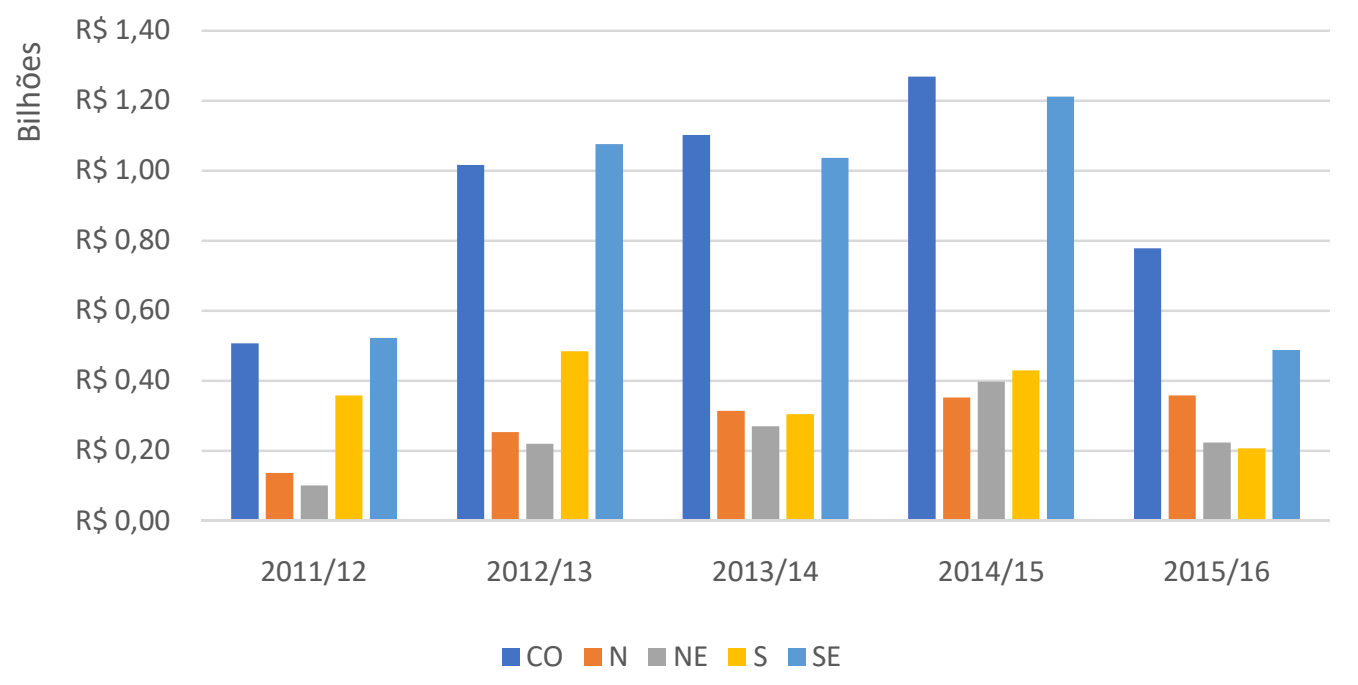

Fonte: Observatório ABC. Disponível em: < http://observatorioabc.com.br/sistema-abc/>

No que se refere à distribuição dos recursos do Programa ABC por subprograma (Tabela 1), nota-se que, para a safra 2015/2016, última safra com os dados completos disponibilizados pelo Observatório $\mathrm{ABC}$, quase metade dos recursos foi direcionada para recuperação de pastagens (48\%). Por outro lado, tanto tratamento de dejetos animais quanto fixação biológica de nitrogênio não tiveram recursos alocados, mas vale a ressalva que $10 \%$ do total está classificado como não disponível, ou seja, não foi possível saber a destinação correta destes recursos. Assim, pode-se até ter recursos para essas duas finalidades, porém não foi possível diagnosticar, com precisão, esta informação (Tabela 1).

Tabela 1 - Desembolso do programa ABC por safra e por finalidade de investimento, com todos os subprogramas incluídos no programa ABC (em R\$).

\begin{tabular}{|c|c|c|c|c|c|c|}
\hline $\begin{array}{l}\text { Finalidade de } \\
\text { Investimento }\end{array}$ & $2011 / 12$ & $2012 / 13$ & $2013 / 14$ & $2014 / 15$ & $2015 / 16$ & $2016 / 17$ \\
\hline $\begin{array}{l}\text { Recuperação de } \\
\text { pastagens }\end{array}$ & $979.512 .776,60$ & $1.455 .418 .442,08$ & 0,00 & 0,00 & $982.637 .916,80$ & $52.411 .527,70$ \\
\hline Plantio Direto & $95.396 .082,43$ & $182.309 .396,49$ & 0,00 & 0,00 & $558.935 .321,53$ & $15.887 .803,89$ \\
\hline Florestas & $142.946 .180,46$ & $121.102 .463,51$ & 0,00 & 0,00 & $117.111 .144,50$ & $3.263 .812,63$ \\
\hline Integração & $54.322 .876,55$ & $95.659 .269,23$ & 0,00 & 0,00 & $90.079 .042,99$ & $13.230 .675,41$ \\
\hline Dejetos & $9.905 .381,44$ & $7.379 .728,90$ & 0,00 & 0,00 & $9.581 .623,07$ & $518.650,00$ \\
\hline Fixação & 0,00 & $1.120 .000,00$ & 0,00 & 0,00 & $2.000 .000,00$ & 0,00 \\
\hline Não disponível ${ }^{1}$ & 0,00 & $1.065 .879 .669,10$ & $3.027 .417 .410,56$ & $3.659 .130 .676,68$ & $197.229 .035,23$ & 0,00 \\
\hline Ambiental & $886.539,70$ & $21.685 .635,07$ & 0,00 & 0,00 & $7.690 .172,23$ & $169.677,00$ \\
\hline Orgânicos & $1.693 .261,76$ & $207.057,46$ & 0,00 & 0,00 & $527.613,07$ & 0,00 \\
\hline Orizicultura & $2.791 .990,90$ & 0,00 & 0,00 & 0,00 & 0,00 & 0,00 \\
\hline Agr baixo carbono & $263.271 .946,44$ & 0,00 & 0,00 & 0,00 & 0,00 & 0,00 \\
\hline Fundos & 0,00 & 0,00 & 0,00 & 0,00 & $79.951 .517,73$ & $15.677 .556,41$ \\
\hline FNO & 0,00 & 0,00 & 0,00 & 0,00 & $7.493 .448,49$ & 0,00 \\
\hline FCO pro natureza & $74.136 .349,50$ & $98.922 .637,67$ & 0,00 & 0,00 & 0,00 & 0,00 \\
\hline
\end{tabular}

Fonte: Observatório ABC. Disponível em: < http://observatorioabc.com.br/sistema-abc/>

Notas: 1 - Quando não é possível determinar a finalidade do desembolso, o Observatório $\mathrm{ABC}$ caracteriza como "Não disponível" 
No que se refere a recuperação de pastagens, responsável por $78 \%$ dos recursos executados do programa ABC no período 2012/2013, Dias-Filho (2014) alerta para a dificuldade de se calcular as áreas de pastagens degradadas no Brasil, principalmente pelo fato das divergências no conceito do que seria considerado pastagem degradada. Entretanto, o autor estimou que cerca de 75\% das áreas de pastagens no Brasil apresentam algum grau de degradação, sendo que 50\% estariam fortemente degradadas.

Nessa perspectiva, Oliveira e Corsi (2005) ainda afirmam que se para cada hectare de pastagem degradada no país se adotasse apenas as primeiras etapas de recuperação seria possível dobrar a taxa de lotação (de média 1 para 2 UA/ha), tornando possível duplicar o rebanho nacional sem avançar em nenhum hectare a fronteira agrícola. Sendo, portanto, justificável a concentração dos recursos do Programa $\mathrm{ABC}$ para esta finalidade, há de se destacar também que a recuperação de pastagens parece bastante viável e palatável à sua adoção por parte dos pecuaristas, tanto pelo seu retorno em produtividade quanto por sua relativa simplicidade frente a sistemas mais complexos como a ILPF por exemplo.

Ao se analisar a distribuição dos recursos do Programa ABC por estado, como mostra a Tabela 2, para a safra 2015/2016, Goiás foi o principal estado beneficiado com os créditos deste programa, com 17,84\% do valor total contratado, seguido por Minas Gerais, Mato Grosso, São Paulo e Mato Grosso do Sul, com respectivamente, 13,34\%, 12,08\%, 9,47\% e 7,91\%. Na outra extremidade, Alagoas, Amazonas, Amapá e Sergipe não captaram recursos do programa $\mathrm{ABC}$ na safra $2015 / 2016$.

Tabela 2 - Desembolso do programa ABC por safra e por estado (em R\$)

\begin{tabular}{l|r|r|r|r|r|r}
\hline \multicolumn{1}{c|}{ Estado } & \multicolumn{1}{|c|}{$\mathbf{2 0 1 1 / 1 2}$} & \multicolumn{1}{|c|}{$\mathbf{2 0 1 2 / 1 3}$} & $\mathbf{2 0 1 3 / 1 4}$ & $\mathbf{2 0 1 4} / \mathbf{1 5}$ & $\mathbf{2 0 1 5} / \mathbf{1 6}$ & \multicolumn{1}{|c|}{$\mathbf{2 0 1 6 / 1 7}$} \\
\hline AC & $2.733 .863,13$ & $17.071 .117,40$ & $18.428 .814,49$ & $23.411 .823,02$ & $25.666 .427,96$ & $1.794 .853,85$ \\
AL & $9.500,00$ & 0,00 & 0,00 & $1.701 .043,81$ & 0,00 & 0,00 \\
AM & $867.996,84$ & 0,00 & 0,00 & $1.787 .545,05$ & 0,00 & 0,00 \\
AP & $39.830,00$ & $1.542 .161,27$ & $1.519 .423,41$ & $2.518 .882,42$ & 0,00 & 0,00 \\
BA & $69.401 .236,26$ & $165.159 .339,25$ & $191.923 .809,50$ & $255.149 .418,34$ & $121.505 .123,87$ & $2.978 .079,19$ \\
CE & $500.000,00$ & 0,00 & $185.895,00$ & 0,00 & $50.016,00$ & 0,00 \\
DF & 0,00 & $1.083 .444,27$ & $356.131,38$ & $903.997,83$ & $1.199 .536,09$ & 0,00 \\
ES & $33.218 .497,31$ & $29.966 .567,41$ & $43.653 .971,80$ & $38.594 .582,49$ & $14.194 .492,73$ & $1.814 .695,00$ \\
GO & $169.702 .320,27$ & $299.980 .270,74$ & $421.878 .074,27$ & $527.024 .077,66$ & $366.238 .304,32$ & $8.160 .419,46$ \\
MA & $14.229 .790,42$ & $28.224 .454,54$ & $55.694 .319,85$ & $99.605 .268,96$ & $58.436 .193,63$ & $10.334 .071,19$ \\
MG & $282.258 .202,12$ & $574.738 .744,38$ & $546.621 .309,23$ & $645.912 .168,20$ & $273.909 .710,46$ & $14.977 .568,04$ \\
MS & $181.202 .029,95$ & $394.854 .639,20$ & $406.038 .010,36$ & $366.436 .519,23$ & $162.364 .522,91$ & $3.786 .725,91$ \\
MT & $156.102 .529,48$ & $320.222 .671,99$ & $273.595 .037,72$ & $374.717 .521,43$ & $248.077 .214,83$ & $474.727,80$ \\
PA & $41.999 .939,09$ & $62.946 .431,76$ & $82.825 .639,55$ & $87.430 .414,09$ & $109.484 .500,23$ & $18.270 .618,22$ \\
PE & $46.800,00$ & $1.494 .045,95$ & $1.638 .772,34$ & $5.124 .850,50$ & $4.062 .341,12$ & 0,00 \\
PI & $17.072 .004,11$ & $24.697 .464,96$ & $19.957 .380,84$ & $35.568 .906,58$ & $37.568 .315,03$ & 0,00 \\
PR & $144.657 .201,38$ & $212.883 .407,62$ & $139.145 .197,35$ & $171.867 .608,88$ & $71.190 .423,66$ & $19.954 .595,80$
\end{tabular}




\begin{tabular}{l|r|r|r|r|r|r}
\hline \multicolumn{1}{c|}{ Estado } & \multicolumn{1}{|c|}{$\mathbf{2 0 1 1 / 1 2}$} & \multicolumn{1}{c|}{$\mathbf{2 0 1 2 / 1 3}$} & \multicolumn{1}{|c|}{$\mathbf{2 0 1 3 / 1 4}$} & $\mathbf{2 0 1 4 / 1 5}$ & $\mathbf{2 0 1 5 / 1 6}$ & $\mathbf{2 0 1 6 / 1 7}$ \\
\hline RJ & $2.229 .160,70$ & $15.200 .505,48$ & $12.191 .222,24$ & $8.285 .980,22$ & $4.695 .553,55$ & 0,00 \\
RN & 0,00 & 0,00 & $970.000,00$ & 0,00 & $1.510 .000,00$ & 0,00 \\
RN & 0,00 & 0,00 & $970.000,00$ & 0,00 & $1.510 .000,00$ & 0,00 \\
RO & $19.829 .170,49$ & $35.287 .826,79$ & $34.083 .976,05$ & $36.025 .743,10$ & $64.513 .213,45$ & $1.891 .886,95$ \\
RR & $1.851 .503,32$ & $5.097 .768,98$ & $4.564 .898,94$ & $5.349 .999,56$ & $7.302 .485,78$ & $1.300 .925,74$ \\
RS & $171.394 .903,18$ & $228.155 .342,14$ & $136.583 .371,68$ & $217.577 .291,27$ & $117.031 .422,80$ & $4.899 .100,41$ \\
SC & $41.722 .761,64$ & $43.028 .726,47$ & $29.076 .146,93$ & $39.422 .457,25$ & $18.667 .512,50$ & $3.580 .132,08$ \\
SE & 0,00 & $582.739,38$ & $59.969,26$ & $33.080,00$ & 0,00 \\
SP & $204.923 .749,32$ & $456.497 .218,90$ & $434.076 .926,80$ & $519.079 .222,85$ & $194.464 .232,68$ & $2.518 .650,00$ \\
TO & $68.870 .396,77$ & $130.969 .410,63$ & $172.349 .111,57$ & $195.602 .273,94$ & $151.105 .292,04$ & $4.422 .653,40$ \\
\hline
\end{tabular}

Fonte: Observatório ABC. Disponível em: < http://observatorioabc.com.br/sistema-abc/>

Há de se destacar também a existência de linhas de financiamento que pouco ou nada têm a ver com a redução de emissões GEE, mas mesmo assim, inicialmente foram incorporados ao programa, como, por exemplo, ABC Ambiental e ABC Orgânico. Embora esses dois programas apresentassem linhas financiáveis com grande sinergia, a sua fusão acabou misturando práticas agropecuárias de baixa emissão de carbono com outras não comprovadamente mitigadoras de emissão de GEE. Outras linhas de financiamento que foram incorporadas ao programa $\mathrm{ABC}$ sem a comprovação científica de que possam mitigar emissões GEE são: $A B C$ Orgânico e o $A B C$ Ambiental. Isso faz com que a eficiência do programa diminua, apesar de essas duas linhas, em conjunto, não representarem mais do que $1 \%$ do recurso total executado pelo programa, no acumulado desde a safra $2011 / 2012$.

O Observatório ABC (2013a) destaca um indicador relevante: reais despendidos via Programa ABC por hectare de pastagem degradada. Na safra 2011/2012, foram alocados, em média, $\mathrm{R} \$ 2,72 /$ ha de pastagem degradada, enquanto que na safra 2012/2013 o indicador saltou para $R \$ 5,25 /$ ha. No entanto, o valor mínimo necessário, segundo cálculos da Embrapa, é de $\mathrm{R} \$ 300 / \mathrm{ha}$, sinalizando que ainda há espaço para estimular o uso e, eventualmente, ampliar o programa no que tange a esta finalidade.

Os dados até agora apresentados mostram que o programa $\mathrm{ABC}$ está, mesmo que a passos lentos, crescendo. No entanto, ainda está aquém do ideal. Um dado que corrobora essa informação é que, ao final da safra 2013/2014, a porcentagem de aplicação dos recursos foi de $67 \%$.

Observatório ABC (2013b) aponta algumas explicações para este elemento fundamental relacionado à implementação da política, que é pertinente à estrutura bancária de repasse dos recursos: os agentes bancários relataram a dificuldade de 
os produtores rurais cumprirem com a burocracia, somada ao fato da disponibilidade de outras linhas de crédito com taxas de juros semelhantes ao ABC, porém com menos obrigações burocráticas quanto à elaboração do projeto técnico.

Além disso, segundo o próprio Observatório ABC (2013b), o baixo diálogo entre as políticas estaduais (e até municipais) e o Plano Nacional do ABC pode explicar a não adesão plena dos produtores ao programa.

Soma-se a isto o fato da agricultura de base familiar também ter pouco acesso ao programa $\mathrm{ABC}$, visto que para aquela existem programas concorrentes ao programa $\mathrm{ABC}$. No que tange o acesso ao crédito para a agricultura familiar, destaca-se o Programa Nacional de Fortalecimento da Agricultura Familiar (Pronaf). Das 12 linhas de crédito existentes no Pronaf, vale destacar as duas que têm relação direta com a agropecuária sustentável²:

- Pronaf Eco: Linha para o financiamento de investimentos em técnicas que minimizam o impacto da atividade rural ao meio ambiente, bem como permitam ao agricultor melhor convívio com o bioma em que sua propriedade está inserida.

- $\quad$ Pronaf Floresta: Financiamento de investimentos em projetos para sistemas agroflorestais; exploração extrativista ecologicamente sustentável, plano de manejo florestal, recomposição e manutenção de áreas de preservação permanente e reserva legal e recuperação de áreas degradadas.

As outras linhas de crédito são: Agroecologia, Custeio, Mais alimentos, Agroindústria, Semiárido, Mulher, Jovem, Custeio e Comercialização de Agroindústrias Familiares, Cota-Parte e Microcrédito Rural.

Outras fontes de financiamento que merecem destaque são os fundos constitucionais, que apresentam condições mais vantajosas para o produtor. Inicialmente, o Fundo Constitucional Centro Oeste (FCO) apresentou uma linha de financiamento denominada FCO-Natureza, que contempla as ações do programa $\mathrm{ABC}$ oferecendo juros menores, de 3\% a.a. Posteriormente, criaram-se suas linhas específicas também denominadas programa $A B C$, que desembolsavam os recursos

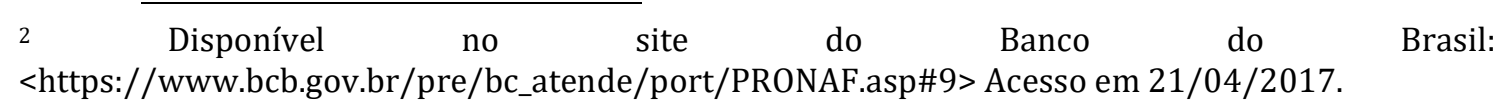


para as mesmas finalidades do programa $\mathrm{ABC}$ (mas não especificamente do Programa $\mathrm{ABC}$ ), mas com taxas de juros mais baixas, a saber: nos fundos constitucionais, as taxas variam entre 3,53\%a.a e 4,12\%a.a, contra 5\% do programa $\mathrm{ABC}$ (Observatório ABC, 2013a).

Apesar de os recursos serem bem-vindos, pois visam a redução de emissões GEE no Brasil, tanto a Poupança Rural (BB) quanto os Fundos Constitucionais (FCO, FNE, FNO), não foram previstos na concepção do programa ABC, apesar de que seus objetivos são expressamente ambientais.

Ainda nesta questão de linhas de financiamentos que rivalizam com o programa $\mathrm{ABC}$ devem ser destacados o Moderfrota, Moderinfra e Moderagro que, apesar de praticarem em alguns anos taxa de juros um pouco mais altas do que as cobradas no Programa do ABC, têm menores graus de exigências na elaboração do projeto técnico do que as exigidas no Programa $A B C$, visto que o foco do Moderfrota, Moderinfra e Moderagro não está voltado a ações para mitigação da emissões GEE. Fica a critério do produtor rural escolher a linha de financiamento que mais lhe seja apropriada, mas pode-se apontar, no que diz respeito tanto à burocracia quanto à taxa de juros, que os programas sem a obrigatoriedade de redução de emissões GEE apresentam algumas vantagens quando comparados ao programa $\mathrm{ABC}$, principalmente no que diz respeito a elaboração do projeto de financiamento. 0 projeto para obtenção de financiamento via $\mathrm{ABC}$ deve ser elaborado por consultores especializados, devido a sua complexidade.

Por outro lado, CNA (2012) destaca que, para determinados itens financiáveis, os programas não são concorrentes. Por exemplo, as máquinas e equipamentos de fabricação nacional para a agropecuária são financiáveis pelo programa $\mathrm{ABC}$ e não são financiáveis pelo Moderfrota e Moderinfra.

Outra questão que merece ser discutida é a da alocação de recursos e as regiões que mais emitem GEE. Nesse sentido, Observatório ABC (2014) destaca que, no que se refere à questão de pastagens degradadas, as regiões com altos índices de degradação (Norte e Nordeste) estão captando recursos do programa do $\mathrm{ABC}$ aquém do necessário, principalmente se comparados ao montante captado pelas outras regiões (principalmente Sudeste e Centro Oeste). 
Em praticamente todos os relatórios publicados pelo Observatório $\mathrm{ABC}$ destaca-se a importância de monitoramento do balanço de mitigação atrelado ao montante desembolsado pelo programa ABC. Dados desta natureza darão subsídio para análises mais qualificadas. Até o presente momento, não há notícias de concretização da iniciativa do MAPA, que havia ficado encarregado de criar o Laboratório Virtual Multi-institucional de Mudanças Climáticas, e que coordenaria o monitoramento do Plano ABC (Observatório ABC, 2013b).

Outro gargalo da política de crédito rural, como um todo, é a deficiência de verificação bancária quanto ao cumprimento de exigências de Reserva Legal e Área de Preservação Permanente. Isso é relevante pois o pagamento do ITR está diretamente relacionado com essas áreas de preservação e para obtenção de crédito rural oficial, é necessário a apresentação do comprovante de pagamento do ITR e, se as áreas não estão corretamente definidas, a alíquota do imposto fica distorcida.

\subsection{POLÍTICA DE GARANTIA DE PREÇOS MÍNIMOS}

Bacha (2012) define a política de garantia de preços mínimos como sendo um mecanismo de política de rendas da agropecuária para minimizar as variações de preços recebidos pelos produtores.

A ideia dessa política é fixar, antes do plantio, um preço mínimo para cada produto, e que pode variar de acordo com a região. O Governo Federal se compromete na colheita a adquirir o produto pelo preço mínimo, se o preço de mercado ficar abaixo deste preço. Esse mecanismo é denominado Aquisição do Governo Federal (AGF). Outro mecanismo, complementar à AGF, é o Empréstimo do Governo Federal (EGF), evitando, assim, que o governo federal forme altos estoques. Nesse caso, o governo viabiliza empréstimos aos produtores para eles estocarem os produtos e vendê-los na entressafra. Deve-se destacar que a AGF e EGF implicam liberação de recursos por parte do Tesouro Nacional (ver Bacha, 2012).

Em 1997, o governo federal iniciou outros programas de garantia de preços com características seletivas. É o caso do Contrato de Opções de Vendas de Produtos Agrícolas (COVPA) e do Prêmio para Escoamento de Produto (PEP). 
O COVPA é um seguro contra queda de preços, mas o produtor paga por este seguro. 0 governo federal (através da Conab) leiloa contratos que preveem aquisição de produtos específicos, em datas especificas, depositados em locais específicos e com preço predeterminado. 0 produtor compra o contrato pagando um prêmio ao governo federal. Vale destacar que o COVPA é seletivo, pois se aplica a poucos produtos, para certas regiões e para os produtores que compram esse seguro (Bacha, 2012).

O PEP é uma subvenção econômica concedida àqueles que se disponham a adquirir o produto indicado pelo Governo Federal, diretamente do produtor rural (ou de sua cooperativa), pelo valor do preço mínimo fixado, promovendo o seu escoamento ou destinação na forma definida em aviso específico, divulgado pela Conab (Bacha, 2012).

O mecanismo do PEP envolve três atores econômicos: o Governo Federal, os produtores (cooperativas) e os arrematantes (indústrias ou comerciantes). Basicamente, o Governo Federal garante ao produtor a compra de um produto pelo seu preço mínimo (via AGF ou COVPA). Se o preço de mercado for menor que o preço mínimo, o produtor vende o produto ao governo, que evita estocá-lo. Para tanto, o Governo Federal faz um leilão de prêmios para um arrematante adquirir o produto diretamente do produtor.

A Lei no 11.076, de 30/12/2004, instituiu dois novos instrumentos de subvenção ao setor privado para assumir parte das atividades de garantia de preços aos produtos agropecuários, o Prêmio Equalizador Pago ao Produtor (Pepro) e o Prêmio de Risco de Opção Privada (Prop).

O Prop (semelhante ao COVPA) é uma subvenção econômica (prêmio) concedida em leilão público ao segmento de intermediação, que se disponha a adquirir (em data futura) determinado produto diretamente de produtores e/ou de suas cooperativas, pelo preço de exercício fixado e nas unidades da federação estabelecidas pelo governo, utilizando-se para isso do lançamento, em leilão privado, de contrato privado de opção de venda. O produtor compra esta opção de venda e caso o intermediário tenha prejuízo de comprar o produto a preço superior ao de mercado, esse prejuízo é coberto até o limite do Prop (Bacha, 2012). 
O Pepro (semelhante ao PEP) é um instrumento de garantia de preço mínimo (subvenção econômica) ao produtor, sem a aquisição do produto pelo governo federal, mediante o pagamento da diferença entre o preço mínimo e o de mercado. 0 pagamento é feito, diretamente, ao produtor rural (ou a sua cooperativa), eliminando, assim, o agente intermediário. Ou seja, de 1997 para cá, o governo mantém a política de garantia de preço mínimo, mas evita participar diretamente do processo, atuando apenas como um regulador deste instrumento de política econômica. Desta forma, além de efetivamente assumir um papel de regulador e não de "estado produtor", o custo do governo federal em operacionalizar os instrumentos da política de preços mínimos, atualmente, é menor do que com o emprego dos tradicionais AGF e EGF.

Dentre os produtos incluídos na PGPM, é interessante destacar os originários do extrativismo, por auxiliarem na manutenção das florestas nativas. Assim, para garantir a sustentação dos preços de produtos extrativistas, foi criada, em 2009, a Política de Garantia de Preços Mínimos para os Produtos da Sociobiodiversidade (PGPM-Bio), como parte do Plano Nacional de Promoção das Cadeias de Produtos da Sociobiodiversidade (PNPSB), visando, basicamente, apoiar o extrativismo sustentável, para contribuir com a conservação e o uso racional dos recursos naturais.

O PPA federal de 2016-2019 inclui a PGPM-Bio no programa referente à Conservação e Uso Sustentável da Biodiversidade (programa 2078), principalmente no que se refere à conservação do meio ambiente por meio da elevação de renda e inclusão social e produtiva (objetivo 1065). Uma das iniciativas preconizadas nesse objetivo é a ampliação do acesso dos produtores extrativistas ao mercado, por meio de ações de divulgação, capacitação e inclusão de novos produtos da sociobiodiversidade na PGPM-Bio, o que denota a importância dada, pelo governo federal, a este tipo de política com viés sustentável.

A Conab é responsável por planejar, normatizar e executar a PGPM e a PGPM-Bio. O MAPA, juntamente com o Ministério da Fazenda, o Ministério do Planejamento, Orçamento e Gestão e o Conselho Monetário Nacional, define os 
preços mínimos de comercialização dos produtos agrícolas, pecuários e extrativos amparados pela política e que são instituídos por meio de portaria publicada no Diário Oficial da União.

A Portaria Interministerial no 254, de 27 de agosto de 2008, formada pelo MMA, MAPA e MDAS, criou um grupo de trabalho interministerial (GTI) para subsidiar as ações voltadas à comercialização de produtos oriundos do extrativismo. Em seu art. 1o, a citada Portaria aprova a proposta de preços mínimos para produtos extrativistas com base em estudos realizados pela Conab. No art. 2o da Portaria citada, a Conab é autorizada a proceder aos estudos necessários para inclusão na PGPM, ainda em 2008, dos seguintes produtos: açaí, andiroba, babaçu, buriti, copaíba, pequi e piaçava; e revisão dos preços mínimos da castanha-do-brasil, borracha natural e cera de carnaúba.

Por sua vez, a Portaria MAPA no 123, de 5 de julho de 2016, definiu os produtos, regiões amparadas e o preço mínimo para os produtos extrativistas no período de vigência de julho/2016 a junho/2017. A Tabela 3 resume as informações de preço mínimo desta portaria.

Viana (2013) aponta que o extrativismo florestal não madeireiro é considerado uma fonte de renda importante para a população que depende desta atividade e peça fundamental para o uso sustentável dos recursos naturais. A PGPM-Bio ainda tem muito a evoluir, segundo as conclusões de Viana (2013). Devido ao alto grau de informalidade das operações de compra e venda desses produtos, os requisitos exigidos pela PGPM-Bio, como nota fiscal, documentação pessoal (física ou jurídica) e a Declaração de Aptidão ao Pronaf (DAP) tornam-se empecilhos ao uso da PGPM-Bio.

A baixa execução pode estar relacionada a, principalmente, dois fatores: o primeiro, já destacado anteriormente, é a percepção dos extrativistas de que a operacionalização do pagamento da subvenção é muito burocrática. A outra é que, por se tratar de política de garantia de preços mínimos, se o preço de mercado for superior ao preço mínimo estabelecido pelo governo, os produtores simplesmente não exercem a opção. Por exemplo, o açaí nunca teve subvenções operacionalizadas, desde o início da PGPM-Bio, pelo simples fato de que o preço de 
comercialização, comumente, esteve superior ao preço mínimo. Outro exemplo citado pelo autor é o da castanha-do-Brasil, em 2011, pelo mesmo motivo do açaí.

Tabela 3 - Produtos selecionados para obtenção da PGPM-Bio e regiões amparadas pela política. Brasil, julho/2016 a junho/2017

\begin{tabular}{l|l|r}
\hline Produto/ Safra & $\begin{array}{l}\text { Unidades da Federação/ Regiões } \\
\text { Amparadas }\end{array}$ & $\begin{array}{l}\text { Preço Mínimo } \\
\text { (R\$/Kg) }\end{array}$ \\
\hline Açaí (fruto) & Norte e Nordeste & 1,29 \\
Andiroba (amêndoa) & Norte e Nordeste & 1,43 \\
Babaçu (amêndoa) & Norte, Nordeste e MT & 2,87 \\
Barú (amêndoa) & Centro-Oeste, MG, SP e TO & 13,22 \\
Borracha Natural (Cernambi) & Norte (exceto TO) e norte do MT & 5,42 \\
Cacau (amêndoa) & 6,22 \\
Carnaúba Cera (bruta gorda) & Nordeste & 13,66 \\
Pó Cerífero - Tipo B & Nordeste & 8,30 \\
Castanha do Brasil com casca & Norte e MT & 1,27 \\
Juçara - fruto & Sul e Sudeste & 2,08 \\
Macaúba (fruto) & Centro-Oeste, Nordeste, Norte e & 0,55 \\
& Sudeste & 2,29 \\
Mangaba (fruto) & Nordeste & 1,63 \\
Pequi (fruto) & Sudeste e Centro-Oeste & 0,56 \\
Piaçava (fibra) & Centro-Oeste, Nordeste, Norte e & 1,91 \\
Pinhão & Sudeste & 2,64 \\
Umbu & Norte e BA & 0,62 \\
\hline Fonte: Portaria Mapa № 123 DE & No5/07/2016. Anexo IV.
\end{tabular}

Este mecanismo é relevante ao analisar as políticas de mitigação pois atua na conservação, preservação e uso sustentável dos recursos naturais, além de fortalecer as comunidades extrativistas e populações tradicionais.

\subsection{POLÍTICA DE PESQUISA AGROPECUÁRIA}

A Lei Agrícola no 8.171, de 17 de janeiro de 1991, no capítulo IV, faz menção à pesquisa agropecuária. No que se refere às suas prioridades, destaca-se a ausência de referências sobre a agricultura de baixo carbono, feita a ressalva que a lei é de 1991. Contudo, em seu artigo 3o, que estabelece seus objetivos, tem-se no inciso IV "proteger o meio ambiente, garantir o seu uso racional e estimular a recuperação dos recursos naturais".

Além do objetivo citado anteriormente, o artigo 4o da citada lei estabelece as ações e instrumentos da política agrícola. Nesse sentido, o inciso IV desse artigo aponta que as ações devam ser pautadas pela proteção do meio ambiente, conservação e recuperação de recursos naturais.

O capítulo IV da Lei Agricola apresenta as diretrizes para a pesquisa agropecuária. 0 quesito preservação do meio ambiente é citado, superficialmente, 
no objetivo de gerar tecnologias de sanidade animal e vegetal. Em síntese, ela não é específica, principalmente no que se refere a questões de mitigação das emissões de GEE.

0 Sistema Nacional de Pesquisa Agropecuária (SNPA) ${ }^{3}$ foi instituído pela Portaria do Mapa no 193, de 7 de agosto de 1992. O SNPA é constituído pela Embrapa, pelas Organizações Estaduais de Pesquisa Agropecuária (OEPAs), por universidades e institutos de pesquisa de âmbito federal ou estadual, além de outras organizações públicas e privadas, direta ou indiretamente vinculadas à atividade de pesquisa agropecuária.

Dentre seus objetivos, destacam-se: “compatibilizar as diretrizes e estratégias de pesquisa agropecuária com as políticas de desenvolvimento definidas para o País, como um todo, e para cada região em particular; favorecer o desenvolvimento de um sistema nacional de planejamento para pesquisa, acompanhamento e avaliação; estabelecer um sistema brasileiro de informação agrícola, com formação de banco de dados para a pesquisa e desenvolvimento agropecuário, facilitando o acesso aos usuários e clientes da pesquisa agropecuária; e, proporcionar a execução conjunta de projetos de pesquisa de interesse comum, fomentando uma ação de parceria entre instituições, no desenvolvimento de ciência e tecnologia para a agropecuária" (Moreira e Teixeira, 2014).

Em 2015, a Embrapa, com outras instituições parceiras, detinha um dos maiores portfólios de pesquisa, no mundo, para redução dos impactos das mudanças climáticas na agricultura: 82 projetos relacionados à interação entre as mudanças climáticas globais e a agricultura ${ }^{4}$ e 449 profissionais da Embrapa trabalhando para adaptar a agricultura e pecuária brasileira às mudanças climáticas.

Em março de 2016, haviam 23 portfólios de pesquisas instituídos em temas de grande importância estratégica, dos quais se destacam: agricultura irrigada,

\footnotetext{
${ }^{3}$ A Lei Agrícola no 8.171, de 17 de janeiro de 1991 faz menção a este Sistema a ser coordenado pela Embrapa e em convênio com estados, DF, territórios e municípios, entidades públicas e privadas, universidade, cooperativa, sindicato, fundações e associações.

4 Para mais detalhes sobre os macroprogramas, portfólios, arranjos e projetos, ver <https://www.embrapa.br/pesquisa-e-desenvolvimento>
} 
fixação biológica de nitrogênio, Integração Lavoura-Pecuária-FLoresta (ILPF), mudanças climáticas, pastagens, impacto do uso de agrotóxicos no meio ambiente. Interessante destacar que a Embrapa possui um portfólio de pesquisa em ILPF com 20 projetos em execução, envolvendo 518 técnicos e pesquisadores da Empresa e 91 parceiros. (Embrapa, 2016).

Dentre as unidades descentralizadas da Embrapa no Brasil, destaca-se a Embrapa Meio Ambiente, unidade de pesquisa de temas básicos, que atua em pesquisa, desenvolvimento e inovação na interface agricultura e meio ambiente, conciliando as demandas dos sistemas produtivos com as necessidades de conservação de recursos naturais e preservação ambiental, com foco na sustentabilidade. Fica localizada em Jaguariúna/SP.

\subsection{POLÍTICA DE EXTENSÃO RURAL}

A extensão rural é também definida pela Lei Agrícola (Lei no 8.171, de 17 de janeiro de 1991). 0 capítulo $V$, em seu artigo 16, estabelece que a assistência técnica e extensão rural “...buscarão viabilizar, com o produtor rural, proprietário ou não, suas famílias e organizações, soluções adequadas a seus problemas de produção, gerência, beneficiamento, armazenamento, comercialização, industrialização, eletrificação, consumo, bem-estar e preservação do meio ambiente."

O serviço oficial de assistência técnica e extensão rural visa, dentre outros objetivos, difundir tecnologias necessárias ao aprimoramento da economia agrícola, conservação de recursos naturais e melhoria das condições de vida no meio rural. Ainda, o art. 18 da Lei Agrícola refere-se à integração entre as ações de assistência técnica e extensão rural com a pesquisa agropecuária, com os produtores rurais, suas entidades representativas e às comunidades locais (Peixoto, 2008).

Outras leis que compõem o arcabouço legal sobre extensão rural e que são mais recentes, devendo, portanto, já refletir com mais ênfase e especificidade as preocupações com as mudanças climáticas e os instrumentos de mitigação consistem na Lei no 12.188/2010: institui a Política Nacional de Assistência Técnica e Extensão Rural para a Agricultura Familiar e Reforma Agrária (PNATER) 
e o Programa Nacional de Assistência Técnica e Extensão Rural na Agricultura Familiar e na Reforma Agrária (Pronater); e a Lei no 12.897/2013 e Decreto no 8.252/2014: que criam a Agência Nacional de Assistência Técnica e Extensão Rural (ANATER).

A PNATER tem como princípios o desenvolvimento rural sustentável, com utilização adequada dos recursos naturais e preservação do meio ambiente e adoção de princípios de agricultura de base ecológica, com enfoque no desenvolvimento de sistemas de produção sustentáveis. Nesse sentido, dentre os objetivos da política que se encaixem no âmbito de mitigação de emissões, destacam-se: promover o desenvolvimento rural sustentável e desenvolver ações voltadas ao uso, manejo, proteção, conservação e recuperação de recursos naturais. Para tanto, as ações voltadas ao cooperativismo, formação de agentes de assistência técnica e extensão rural, para aproximar a produção agrícola e o meio rural do conhecimento científico também são objetivos dessa Política.

Por sua vez, o Pronater é o principal instrumento de implementação da PNATER. Os objetivos são organizar e executar os serviços de Assistencia Técnica e Extensão Rural (Ater). Prevê-se que o Pronater deva ser implementado em parceria com os Conselhos Estaduais de Desenvolvimento Sustentável e da Agricultura Familiar ou órgãos similares.

À ANATER, criada pela Lei no 12.897/2013 e instituída pelo Decreto no 8.252, de 26 de maio de 2014, nos mesmos moldes das leis já citadas sobre extensão rural, compete promover, estimular, coordenar e implementar programas de assistência técnica e extensão rural, visando à inovação tecnológica e à apropriação de conhecimentos científicos de natureza técnica, econômica, ambiental e social. O conselho de administração da ANATER - que delibera e aprova questões relativas a orçamento, planejamento estratégico, plano de trabalho, dentre outras competências - é formado pelo MDA, Mapa, Confederação Nacional dos Trabalhadores na Agricultura (Contag), Federação dos Trabalhadores e Trabalhadoras na Agricultura Familiar (Fetraf), CNA, Organização das Cooperativas Brasileiras (OCB) e representantes de governos estaduais. Além do conselho administrativo, o decreto no 8.252/2014 também define o conselho 
assessor nacional, que, apesar de seu caráter consultivo, é formado por 36 membros, entre ministérios, institutos, bancos, associações, federações, confederações e representantes de classes afetadas diretamente pela agência.

Descrita a base legal, é importante avaliar como, na prática, essas políticas e programas de extensão rural estão operando e é nesse contexto que cabe enfatizar que o Observatório ABC (2013b) destaca que o principal problema do Programa $\mathrm{ABC}$ é a dificuldade de ser implementado. Foram diagnosticadas também deficiências crônicas no sistema de extensão rural, mesmo que no Brasil haja muitas instituições capacitadas para exercer funções de extensão rural, tais como Associação Brasileira de Assistência Técnica e Extensão Rural (Asbraer), a CNA, a OCB, a Embrapa e as universidades (no Brasil há 273 universidades com cursos de Ciências Agrárias). Em tese, ao todo, são mais de 7.000 bases de apoio para o Plano, e isso sem considerar empresas e ONGs. Porém, apesar de muitas organizações que, teoricamente, poderiam contribuir com ações de extensão rural, deve ser ressaltado que muitas delas possuem estrutura (física, humana e financeira) mínima para realizar atividades de extensão rural.

Alves et al. (2016) alertam para o fato de que o principal gargalo da extensão rural não é a comunicação de novas tecnologias e sim que essas tecnologias só serão incorporadas pelas empresas se forem lucrativas. Assim, o desafio da extensão rural é sensibilizá-los a maximizar a mitigação das emissões sujeito a um lucro mínimo, dadas as condições específicas de cada propriedade rural.

No que se refere à tecnologia, é apontada como o fator principal pela elevada concentração da produção, visto que muitos estabelecimentos produziram muito pouco ao passo que um pequeno grupo foi responsável pela maior parte da produção, com base nos dados do Censo Agropecuário de 2006. Pode-se dizer que a tecnologia é a responsável pelo sucesso do agronegócio brasileiro, o que já ficou evidenciado em Gasques et al. (2016), que evidenciaram esse crescimento pelos ganhos na produtividade tanto da mão de obra quanto da terra, que, respectivamente, apresentaram taxas de crescimento anuais de 5,32\% e 4,7\%, para o período 2000 a 2014 . 
Além das instituições públicas de extensão rural (federais, estaduais e municipais), Alves et al. (2016) destacam ainda o Serviço Nacional de Aprendizagem Rural (Senar), criado pela Lei no 8.315, de 23 de dezembro de 1991, é uma entidade de direito privado, paraestatal vinculada à CNA. Para esta entidade, os dados de funcionários no ano de 2015, separados por cadeias produtivas e funções são apresentados na Tabela 4.

Tabela 4 - Quadro de funcionários do SENAR no ano de 2015 separados por cadeia produtiva, Brasil

\begin{tabular}{|c|c|c|c|c|c|}
\hline Cadeia & $\begin{array}{l}\text { Engenheiro } \\
\text { agrônomo }\end{array}$ & $\begin{array}{l}\text { Médico } \\
\text { veterinário }\end{array}$ & $\begin{array}{l}\text { Técnico } \\
\text { Agropecuária }\end{array}$ & Zootecnista & Total \\
\hline $\begin{array}{l}\text { Bovinocultura de } \\
\text { leite }\end{array}$ & 79 & 196 & 206 & 86 & 567 \\
\hline $\begin{array}{l}\text { Cadeias } \\
\text { diversas }\end{array}$ & 6 & - & 92 & 4 & 102 \\
\hline Cafeicultura & 10 & 3 & 30 & - & 43 \\
\hline $\begin{array}{l}\text { Bovinocultura de } \\
\text { corte }\end{array}$ & 6 & 4 & - & 6 & 16 \\
\hline $\begin{array}{l}\text { Caprino- } \\
\text { ovinocultura }\end{array}$ & 2 & - & 10 & - & 12 \\
\hline Horticultura & 7 & - & 4 & - & 11 \\
\hline Cacauicultura & - & 1 & 9 & - & 10 \\
\hline Fruticultura & 5 & - & 3 & - & 8 \\
\hline Total & 115 & 204 & 354 & 96 & 769 \\
\hline
\end{tabular}

Fonte: Senar apud Alves et al. (2016).

Dados sobre a quantidade de profissionais, ou o número de estabelecimentos capacitados para exercer as funções de extensão rural são encontrados, porém as ações que de fato estão sendo feitas não são tão divulgadas e, diferentemente da pesquisa agropecuária, a mitigação das emissões de gases do efeito estufa, a agricultura de baixa emissão de carbono não é prioridade para a extensão agropecuária.

\subsection{POLÍTICA DE ABASTECIMENTO}

O que vale ser destacado sobre a política nacional de abastecimento é o Projeto de Lei no 51, de 2008, que institui a Política Nacional de Abastecimento 5 , mas que ainda não foi aprovado. Neste projeto de lei, a explicação da ementa, que contempla objetivos, princípios e as competências do setor público, não aborda questões referentes à mitigação das emissões e nem sobre sustentabilidade ou produtos da sociobiodiversidade (PGPM-Bio).

5 Disponível em: <http://www25.senado.leg.br/web/atividade/materias/-/materia/84102> Acesso em 21/04/2017. 
Por outro lado, o tema parece contemplado tendo em vista os eixos de ação propostos pelo governo federal, apresentados pelo MAPA sobre o Plano Nacional de Abastecimento, quais sejam: Modernização e Inovação, Qualidade e Segurança Alimentar, Políticas de Sustentabilidade, Informação de mercado e tecnologia da informação, Sistema Nacional de Centrais de Abastecimento e Políticas Públicas de Inserção Produtiva, Ordenamento jurídico e fontes de financiamento.

No que tange à sustentabilidade, as principais ações propostas para a Política visam criar programas de certificação das Ceasas como critério de acesso às linhas de financiamento do BNDES, contemplando aspectos socioambientais. No entanto, a apresentação ${ }^{6}$ não faz menção, em qualquer momento, ao programa $\mathrm{ABC}$.

Como políticas de sustentabilidade, ainda, elencam-se a política nacional da Ater e da Ceasa (papel do estado como indutores de desenvolvimento local e regional) e a certificação dos produtos, rastreabilidade e rotulagem, como forma de agregação de valor aos alimentos comercializados pelas centrais.

Assim, os programas que interagem, direta ou indiretamente, com esta proposta de Política Nacional de Abastecimento são o Programa de Aquisição de Alimentos (PAA) e Programa Nacional de Alimentação Escolar (PNAE).

O PAA foi criado pela Lei no 10.696, de 2 de julho de 2003 e regulamentado pela Lei no 12.512, de 14 de outubro de 2011 e pelo Decreto no 7.775, de 4 de julho de 2012. O programa tem por finalidade incentivar a agricultura familiar, promovendo a sua inclusão econômica e social, com fomento à produção com sustentabilidade, ao processamento, à industrialização de alimentos e à geração de renda e também promover e valorizar a biodiversidade e a produção orgânica e agroecológica de alimentos, e incentivar hábitos alimentares saudáveis em nível local e regional. 0 grupo gestor, responsável pela implementação do PAA, é composto pelos seguintes ministérios: Desenvolvimento Social e Agrário, Fazenda, Agricultura, Pecuária e Abastecimento, Planejamento, Orçamento e Gestão e Educação.

${ }^{6}$ Disponível $\quad$ em: $\quad<$ http://www2.camara.leg.br/atividade-legislativa/comissoes/comissoespermanentes/capadr/audiencias-publicas/audiencias-publicas-2013/audiencia-publica-12-de-novembrode-2013-mapa> Acesso em: 21/04/2017. 
Araújo e Vale (2013) explicitam como os produtos da sociobiodiversidade (estabelecidos na PGPM-BIO) estão inseridos no contexto do PAA. Em 2011, a Conab investiu $\mathrm{R} \$ 450$ milhões no PAA, porém apenas $\mathrm{R} \$ 10$ milhões foram destinados à aquisição de produtos da sociobiodiversidade.

Outro ponto relevante observado por Araújo e Vale (2013) é o Decreto no 7.746, de 5 de junho de 2012, que regulamenta as contratações realizadas pela administração pública federal. Este decreto estabelece critérios, práticas e diretrizes para a promoção do desenvolvimento sustentável, além de instituir a Comissão Interministerial de Sustentabilidade na Administração Pública, a CISAP. Como ressaltado pelos autores, os produtores orgânicos podem receber até $30 \%$ a mais pelos seus produtos escoados via PAA, o que permitiria, portanto, inferir que o programa cumpre com uma de suas finalidades.

Por sua vez, o PNAE foi criado em 1955 e passou por diversas reavaliações, inclusive no art. 207 da Constituição Federal, que destaca o caráter suplementar deste tipo de política. Resumidamente, como retratado no art.4o da Lei no 11.947, de 16 de junho de 2009, o objetivo do PNAE é contribuir para o crescimento e desenvolvimento saudável dos alunos. Este programa é coordenado pelo Fundo Nacional de Desenvolvimento da Educação (FNDE), que repassa os recursos federais para as secretarias estaduais e municipais (Carvalho e Castro, 2009).

Mais relevante do que a questão de repasse dos recursos $^{7}$, o PNAE apresenta modelos que estão atendendo as necessidades locais, regionais, nacional e internacional no âmbito da sustentabilidade, conforme apresentam Carvalho e Castro (2009). Essas autoras ampliam o conceito de sustentabilidade pois abordam questões sociais, culturais, espaciais-territoriais, econômicas, políticoinstitucionais e, principalmente, ecológicas e ambientais.

A sustentabilidade ecológica pode ser observada em alguns casos que ocorreram nos estados de Goiás, Santa Catarina, Paraná e Rio Grande do Sul, por meio de aquisição de alimentos orgânicos, seja em hortas escolares ou na aquisição de produtores locais, fortalecendo a economia municipal e preservando a biodiversidade. A sustentabilidade ambiental, por sua vez, pode ser observada no

${ }^{7}$ Regulamentada pelas seguintes resoluções: Resolução/FNDE no 38/2008 e a Resolução/FNDE no $32 / 2006$. 
município de Cascavel-RS, que substituiu utensílios de plástico por inox, para preservar o meio ambiente. No Rio de Janeiro, há proibição de compra de alimentos geneticamente modificados ou que utilizem agrotóxicos em sua produção para uso na alimentação escolar.

Apesar de as diretrizes dessas políticas sinalizarem para o desenvolvimento sustentável, que teoricamente estaria alinhado às práticas preconizadas pela PNMC (mitigação das emissões), é difícil afirmar que, na prática, isso está acontecendo. As fontes de informação (notas técnicas, artigos, sites oficiais) não permitem tal inferência, pois a fiscalização quanto à implementação das políticas é questionável em todas as regiões do País, e para quaisquer políticas sob execução. De modo que, não é possível afirmar que os programas acima mencionados são complementares ou conflitantes com a PNMC, em virtude dessas limitações.

Diferentemente das outras políticas, em que a agricultura familiar não era retratada especificamente, estes dois programas o PNAE e o PAA, contemplam a agricultura familiar, e este segundo, em particular, representou a base para aquisições institucionais de produtos de origem orgânica pela agricultura familiar, conforme destacam Maciel e Flech (2013).

\section{REGULAÇÃO DO USO DE RECURSOS NATURAIS}

Neste tópico, referente aos recursos naturais, serão abordadas as políticas envolvendo a restrição ao uso de vegetação nativa (em especial o novo código florestal) e a preservação dos recursos hídricos.

\subsection{CÓDIGO FLORESTAL}

A Lei no 12.651, de 25 de maio de 2012 dispõe sobre temas referentes à proteção da vegetação nativa. É importante destacar também a Lei no 12.727 , de 17 de outubro de 2012 que altera, em alguns pontos, o Código Florestal (Lei no 12.651/2012). Outras regulamentações foram dadas pelo Decreto no 7.830, de 17 de outubro de 2012. O principal objetivo do código é estabelecer as regras gerais sobre a exploração da vegetação nativa no território brasileiro.

0 artigo 3o define Área de Preservação Permanente (APP) como "área protegida, coberta ou não por vegetação nativa, com a função ambiental de 
preservar os recursos hídricos, a paisagem, a estabilidade geológica e a biodiversidade" (inciso II). Além da APP, é definido também que Reserva Legal (RL) é a "área localizada no interior de uma propriedade rural com a função de assegurar o uso econômico de modo sustentável dos recursos naturais do imóvel rural, auxiliar a conservação e a reabilitação dos processos ecológicos e promover a conservação da biodiversidade, bem como o abrigo e a proteção de fauna silvestre e da flora nativa" (inciso III).

No que se refere às APP, as considerações do novo código são: para as margens de rio, a área mínima de florestas a ser mantida depende da largura de cada um: rios de até 10 metros de largura devem ter 30 metros de mata preservada; para rios de 10 a $50 \mathrm{~m}$ de largura, $50 \mathrm{~m}$ de mata; de 50 a $200 \mathrm{~m}$ de largura, $100 \mathrm{~m}$ de mata; de 200 a $600 \mathrm{~m}$ de largura, $200 \mathrm{~m}$ de mata; e rios de mais de $600 \mathrm{~m}$ de largura devem ter 500m de mata preservada em suas margens. Para o topo de morros e montanhas devem ser conservadas todas as áreas com altura mínima de 100m e inclinação média maior que 25 graus, e nas encostas, todas as áreas com declividade superior a 45 graus. Para os tabuleiros ou chapadas, devem ser mantidas as bordas até a ruptura do relevo. Já para as nascentes e olhos d'água, a mata mínima preservada deve ter raio de 50 metros de largura e os manguezais devem ter toda a sua extensão conservada. No caso das veredas, a largura mínima da faixa de vegetação a ser preservada é de 50 metros, a partir do espaço permanentemente brejoso e encharcado.

No que refere às RL, o Código determina tamanhos distintos para as mesmas, de acordo com a situação geográfica, sendo de: $80 \%$ da área total do imóvel localizado em áreas de florestas da Amazônia Legal, 35\% no cerrado, 20\% em campos gerais, e 20\% em todos os biomas das demais regiões do País.

O Cadastro Ambiental Rural (CAR) é um registro público eletrônico de âmbito nacional, obrigatório para todos os imóveis rurais e de caráter declaratório, com a finalidade de integrar as informações ambientais das propriedades rurais, compondo base de dados para controle, monitoramento, planejamento ambiental e econômico e combate ao desmatamento. Nesse sentido, o CAR é um instrumento que auxilia o processo de regularização das propriedades rurais (Teixeira Neto e Melo, 2016). 
Almeida et al. (2013) destacam outros resultados positivos da implementação do CAR a nível nacional para além da regularização das propriedades rurais. As informações ambientais das propriedades, ao serem reunidas em uma única base de dados, poderão ser úteis para os outros programas de mitigação de emissões, tanto para os planos setoriais da PNMC (Plano ABC) quanto para os Planos de Ação para a Prevenção e Controle do Desmatamento nos biomas (Cerrado e Amazônia, principalmente). Para esses programas, o CAR aparece como um instrumento tanto de gestão quanto de controle ambiental e monitoramento.

É interessante mencionar que o PPA 2016-2019 contempla compromissos relacionados ao Código Florestal, no objetivo 1064 do programa 2078: Conservação e Uso Sustentável da Biodiversidade, principalmente no que se refere à questão de regularização ambiental, sob responsabilidade do MMA.

As iniciativas que merecem destaque são: acompanhamento da implementação do CAR, aquisição, qualificação e disponibilização de imagens de satélite para o CAR, órgãos públicos e entes federativos e a promoção da recuperação ambiental e uso sustentável das áreas de reserva legal, de preservação permanente para a conservação da biodiversidade e de bacias hidrográficas críticas.

Porém, o CAR apresenta uma série de dificuldades na implementação, como ressaltam Teixeira Neto e Melo (2016): acesso limitado à internet em áreas afastadas, falta de recursos dos governos estaduais para implementação do CAR e outros instrumentos disponibilizados pelo código florestal, e a falta de estrutura física e de servidores para realizar a gestão do CAR. Esses problemas levantados pelos autores podem gerar, na prática, desconfiança, tanto pela falta de informações quanto pelo monitoramento, que ainda está aquém do ideal.

Além das críticas ao CAR, Almeida et al. (2013) e Neves et al. (2015) avaliam de forma negativa o Código Florestal.

De acordo com Soares-Filho et al. (2014, apud Neves et al, 2015), o novo Código de 2012, pode contribuir com a diminuição de até 58\% das áreas que deveriam ser reflorestadas, pois estas áreas foram desmatadas antes da aprovação 
do novo Código, mas foram anistiadas por essa lei federal ${ }^{8}$. Além disso, permite o desmatamento legal de mais 88 milhões de hectares, que antes eram protegidos e deixaram de ser pela instituição desse instrumento normativo ambiental em 2012.

Nesse sentido, Almeida et al. (2013) apontam divergências entre a PNMC e o Código Florestal. Ressaltam que as áreas rurais não precisarão ser restauradas. Assim, áreas que deveriam ser restauradas, segundo esses autores, não entrarão no cômputo das florestas nativas, essenciais para a mitigação das emissões via redução no desmatamento. Além disso, a redução da APP e a inclusão destas no cálculo da RL, reduzirão as áreas que poderiam ser protegidas e/ou recuperadas.

\subsection{POLÍTICA DE RECURSOS HÍDRICOS}

A Política Nacional dos Recursos Hídricos (Lei no 9.433, de 8 de janeiro de 1997) tem como um dos objetivos a utilização racional e integrada dos recursos hídricos. Nesse sentido, para a agropecuária, deve ser destacada a Política Nacional de Irrigação, instituída pela Lei no 12.787, de 11 de janeiro de 2013, que tem como princípios o uso e manejo sustentável dos solos e dos recursos hídricos destinados à irrigação, além de integração com as políticas setoriais de recursos hídricos, de meio ambiente, de energia, de saneamento ambiental, de crédito e seguro rural e seus respectivos planos, com prioridade para projetos cujas obras possibilitem o uso múltiplo dos recursos hídricos e articulação com as diferentes esferas de governo e com o setor privado para as ações em irrigação.

A Política Nacional dos Recursos Hídricos também é contemplada pelo PPA 2016-2019, no Programa 2084, com os objetivos de promover a disponibilidade de água para usos múltiplos, fortalecer os entes do Sistema Nacional de Gerenciamento de Recursos Hídricos, promover a conservação e o uso racional dos recursos hídricos (boas práticas de uso de água e solo e da revitalização de bacias hidrográficas). Ainda no PPA, um dos objetivos do programa 2077 (Agropecuária Sustentável) é a implementação, recuperação e modernização de projetos públicos de irrigação já existentes. Destaque também para as metas regionalizadas, além da regulamentação da Política Nacional de Irrigação.

\footnotetext{
${ }^{8}$ Via uma figura jurídica denominada "área rural consolidada", que é área de imóvel rural com ocupação antrópica preexistente a 22 de julho de 2008, com edificações, benfeitorias ou atividades agrossilvipastoris, admitida, neste último caso, a adoção do regime de pousio.
} 
Christofidis (2013) destaca o aumento das áreas irrigadas no Brasil. Entre 1975 e 2006, a superfície com sistemas de irrigação e drenagem destinadas à agricultura cresceu de 1,1 milhão de ha para 4,5 milhões. A evolução é nítida, porém ainda é lenta. 0 autor destaca a retirada de água da agricultura irrigada para atender às necessidades do meio urbano, da produção industrial, além das exigências ambientais cada vez maiores. Assim, são necessárias melhorias no manejo da agricultura irrigada, incentivo à reconversão de sistemas de irrigação que apresentam baixa eficiência, para sistemas de irrigação adaptados aos cultivos de maior retorno e apropriados ao uso racional de energia e otimização do uso de água.

Em síntese, a relação entre a política (ou lei) de recursos hídricos e mitigação de emissões é justamente a obrigatoriedade da preservação e reposição das matas ciliares, e estas, efetivamente, é que sequestram GEE, particularmente quando estão em formação e crescimento.

Christofidis (2013) afirma que a produtividade com a prática de agricultura irrigada é 2,7 vezes maior do que a obtida pela agricultura tradicional, de sequeiro. Ele destaca a importância da utilização de irrigação, pois melhora o manejo da produção e disponibilidade de água, tanto em qualidade quanto em quantidade. 0 autor destaca que, o aumento de produtividade observado na agricultura brasileira a partir dos anos 1990, pode ser explicado pelos investimentos em modernização da irrigação, equipamentos mais sofisticados, racionalização do plantio. Além do aumento da produtividade, é necessário destacar também o aumento da área que utiliza sistemas de irrigação. De 1975 a 2006, a área aumentou mais de 4 vezes, passando de 1,1 para 4,45 milhões de hectares.

\section{CONSIDERAÇÕES FINAIS}

A literatura sobre políticas agrícolas e ambientais focam principalmente os aspectos de estímulo à produção dado pelas primeiras e o caráter regulatório, das políticas ambientais, visando minimizar os impactos que a agropecuária tem no meio ambiente.

0 presente artigo, de maneira inovadora, buscou avaliar a presença dentro dessas duas políticas (agrícola e ambiental) de programas ou medidas que também 
possam fazer com que a agropecuária mitigue sua emissão de gases causadores do efeito estufa (GEE).

No caso brasileira, a agropecuária é responsável por 31\% da emissão de GEE em 2015, destacando-se a pecuária bovina nessas emissões.

Constatou-se que, apesar de haver programas dentro dessas políticas que contribuem para a mitigação do GEE, esses programas não são os mais destacados dentro dessas políticas. Por exemplo, dentro da política de crédito rural, apenas um programa (o ABC) e subprogramas do Pronaf se preocupam com atividades mitigadoras de emissão de gases causadores do efeito estufa. Considerando o último ano agrícola e pecuário já encerrado (2016/17), dos $R$ \$ 183,8 bilhões previstos de concessão de crédito rural, apenas 1,63\% estavam previstos para 0 Programa ABC. Considerando apenas a importância desse programa no total previsto de crédito de investimento, essa percentagem eleva-se para 2,94\%. Situação similar ocorre nas demais políticas agrícolas. Na PGPM, apenas a partir de 2012 os produtos da biodiversidade passaram a serem contemplados. E a maior parte da pesquisa e extensão se volta para o lado produtivista da agropecuária.

O acima concluído não é, de todo, espantoso, dada as vantagens comparativas em termos edafoclimáticas da agropecuária no Brasil. Considerando que a pecuária bovina é a maior emissora de GEE, esforços de pesquisas visando alterar sua alimentação e tempo de abate podem ser frutíferos para diminuir a emissão de GEE. A discussão dessas possíveis pesquisas fica como sugestão para futuros trabalhos.

\section{BIBLIOGRAFIA}

ALMEIDA, A. M. de. A Política de Garantia de Preços Mínimos - PGPM e a atuação da Companhia Nacional de Abastecimento - CONAB no período após a abertura comercial: mudança institucional e novos instrumentos. 2014. $206 \mathrm{f}$. Tese (Doutorado em Ciências, Área de Concentração: Economia Aplicada) - Escola Superior de Agricultura Luiz de Queiroz, Universidade de São Paulo, Piracicaba, 2014

ALMEIDA, P.S; TIOSSO, A; SILVA, J.S.F. Análises e considerações sobre as influências do Código Florestal brasileiro na política nacional sobre mudança do clima: Lei no 12.651/12 e suas alterações. Revista de estudos ambientais (REA), v.15, n. 2, p. 16-24, jul./dez. 2013. 
ALVES, E. "Embrapa - Um caso bem-sucedido de inovação institucional” In Revista de Política Agrícola, Ano XIX, Edição Especial, julho de 2010, p. 65 a 73.

ALVES, E.R.A; SANTANA, C.A.M; CONTINI, E. Extensão Rural: Seu problema não é a comunicação. In: VIEIRA FILHO, J.E.R; GASQUES, J.G. Agricultura, transformação produtiva e sustentabilidade. Brasília: Ipea, 2016. 391 p. cap.2. p. 65-88.

ARAÚJO, F.C.; VALLE, R.S.T. A política agrícola como vetor para a conservação ambiental. Instituto Socioambiental (ISA). São Paulo, 2013.

ARAUJO, P.F.C.. O Crédito Rural e sua Distribuição no Brasil. Revista de Estudos Econômicos 13(2):232-348, 1983.

BACHA, C.J.C. Economia e política agrícola no Brasil. 2a edição. São Paulo: Atlas, 2012.

BACHA, C.J.C. O Uso de Recursos Florestais e as Políticas Econômicas Brasileiras Uma Visão Histórica e Parcial de um Processo de Desenvolvimento. Revista Estudos Econômicos, São Paulo, vol. 34, n. 2, p. 393 a 426, abril/junho de 2004.

BACHA, C.J.C.; SILVA, G.S. Os novos instrumentos de financiamento do agronegócio. Agroanalysis (FGV), São Paulo, SP, v. 25, no 09, p. 36-37, 2005.

BORSOI, Z.M.F.; TORRES, S.D.A. A Política de Recursos Hídricos no Brasil. BNDES, 1997, texto disponível em https://www.bndes.gov.br/SiteBNDES/export/sites/default/bndes_pt/Galerias/A rquivos/conhecimento/revista/rev806.pdf

BURITI, C.O.; BARBOSA, E.M. Políticas Públicas de Recursos Hídricos no Brasil: olhares sob uma perspectiva jurídica e histórico-ambiental, In Veredas do Direito, Belo Horizonte, v.11, n.22, p.225-254 • Julho/Dezembro de 2014. Disponível em http://www.domhelder.edu.br/revista/index.php/veredas/article/viewFile/431/ 423.

CAFFAGNI, L.C. Seguro rural no Brasil: evolução, alternativas e sugestões. Piracicaba, ESALQ/USP, dissertação de mestrado. 1998, 173 páginas.

CARVALHO, D.G; CASTRO, V.M. O Programa Nacional de Alimentação Escolar PNAE como política pública de desenvolvimento sustentável. VIII ENCONTRO DA SOCIEDADE BRASILEIRA DE ECONOMIA ECOLÓGICA. Cuiabá. Mato Grosso. Brasil. Agosto/2009.

CHRISTOFIDIS, D. Água, irrigação e agropecuária sustentável. Revista de Política Agrícola, Ano XXII, n 1, Jan./Fev./Mar. 2013.

DIAS-FILHO, M.B. Diagnóstico das pastagens no Brasil. Embrapa Amazônia Oriental. Belém-PA. 36p. maio/2014.

GASQUES, J. G.; BACCHI, M. R. P.; RODRIGUES, L.; BASTOS, E. T.; VALDES, C. Produtividade da agricultura brasileira: a hipótese da desaceleração. In: Vieira Filho, J. E. R.; Gasques, J. G. (Org.). Agricultura, transformação produtiva e sustentabilidade. Brasília, DF: Ipea, 2016. p. 143-163.

LIMA, A.L. Extensão rural e modernização da agricultura no Brasil: uma perspectiva histórica. In Santos, M.L.; Vieira, W.C. (Ed.) Agricultura na virada do milênio: velhos e novos desafios. Viçosa, 2000, p. 93-116 - 
MACIEL, C.A.R; FLECH, E.M. O Programa de Aquisição de Alimentos e o estímulo à produção orgânica. Revista Eletrônica do Curso de Direito da UFSM. V8. Edição Especial: I Congresso Internacional de Direito Ambiental e Ecologia Política UFSM. 2013.

NEVES, F.M; CHANG, M; PIERRI, N. As estratégias de enfrentamento das mudanças climáticas expressas nas políticas públicas federais do Brasil. Desenvolvimento e Meio Ambiente - UFPR, v. 34, p. 5-23, ago. 2015.

OBSERVATÓRIO ABC. Agricultura de Baixa Emissão de Carbono: A evolução de um novo paradigma - Sumário Executivo. 2013b.

OBSERVATÓRIO ABC. Agricultura de Baixa Emissão de Carbono: Financiando a transição: Análise dos recursos do Programa ABC. Sumário Executivo. 2013.

OLIVEIRA, P.P.A.; CORSI, M. Recuperação de pastagens degradadas para sistemas intensivos de produção de bovinos. Circular Técnica 38 (Embrapa). São Carlos SP. 2005.2 Disponível em: <https://ainfo.cnptia.embrapa.br/digital/bitstream/CPPSE/15659/1/Circular38.p df $>$ Acesso em 26/04/2017.

OZAKI, V.A. Em busca de um novo paradigma para o seguro rural no Brasil, Revista de Economia e Sociologia Rural, volume 46, n. 01, p. 97 a 119, janeiro de 2008.

PAIXÃO, M.A.S.; BACHA, C.J.C. A agropecuária brasileira e sua inserção na Economia Verde: uma análise do Plano e Programa ABC. Revista Pesquisa \& Debate, volume 26, número 1 (47), p.75-98, São Paulo, jan-mar/2015.

PEIXOTO, M. Mudanças e desafios da extensão rural no Brasil e no mundo. In Buainain, A. M. et.al. (editores técnicos) 0 mundo rural no Brasil do século 21, Brasília: Embrapa, 2014, p. 891 a 924

PORTUGAL, A.D.; CONTINI, E. O público e o privado na pesquisa agropecuária brasileira. In 35o Congresso Brasileiro de Economia e Sociologia Rural, agosto de 1997, p. 38 a 52

REZENDE, G.C. A Evolução da Política de Preços Mínimos na Década de 1990 In GASQUES, J.G.; CONCEIÇÃO, J.C.P.R. Transformações da Agricultura e Políticas Públicas. Brasília: IPEA, 2001, p. 303-314.

SAYAD, J. Crédito Rural no Brasil: Avaliação das Críticas e das Propostas e Reforma. São Paulo. FIPE e Pioneira. 125p. 1984.

STEFANELO, E. L. A política de garantia de preços mínimos no Brasil: classificação e operacionalização dos seus instrumentos no período 1990-2004. 2005. 176 f. Tese (Doutorado em Engenharia de Produção) - Universidade Federal de Santa Catarina, Florianópolis, Santa Catarina, 2005.

TEIXEIRA NETO, E.S.F; MELO, J.A.M. Cadastro Ambiental Rural, CAR - Um Estudo sobre as principais dificuldades relacionadas a sua implantação. Negócios em Projeção, volume 7, número 2, ano 2016, p.54-68. 